\title{
Acute effects of interferon- $\alpha$ administration on testosterone concentrations in healthy men
}

\author{
E P M Corssmit, E Endert, H P Sauerwein and J A Romijn ${ }^{1}$ \\ Department of Endocrinology and Metabolism of Academic Medical Center, Meibergdreef 9, 1105 AZ Amsterdam, \\ The Netherlands and ${ }^{1}$ Department of Endocrinology and Metabolism, Leiden University Medical Center, PO Box 9600,2300 RC Leiden, \\ The Netherlands \\ (Correspondence should be addressed to E P M Corssmit, Department of Endocrinology, F4-222, Academic Medical Center, Meibergdreef 9, \\ 1105 AZ Amsterdam, The Netherlands; Email: E.P.Corssmit@amc.uva.nl)
}

\begin{abstract}
Objective: Recombinant human interferon alpha $(\operatorname{rhIFN}-\alpha)$ is used therapeutically in malignant disorders and chronic hepatitis. The present study was assessed to study the effects of rhIFN- $\alpha$ on the hypothalamic-pituitary-testicular (HPT) axis.

Design and methods: We performed a saline-controlled cross-over study in six healthy men, sequentially measuring the serum concentrations of gonadotropins, testosterone, the free androgen index (FAI) and sex hormone-binding globulin (SHBG) after a bolus subcutaneous injection of rhIFN- $\alpha$.

Results: rhIFN- $\alpha$ induced a sustained decrease of both testosterone (from $19.5 \pm 1.88$ to a nadir of $5.49 \pm 0.51 \mathrm{nmol} / \mathrm{l}$ at the end of the study) and FAI (from $98.7 \pm 14.7$ to a nadir of $32.1 \pm 5.3$ at the end of the study), whereas concentrations of LH, FSH and SHBG were not different between the two studies.

Conclusions: Our results suggest that rhIFN- $\alpha$ affects the HPT axis at the testicular level, either directly or indirectly, and changes feedback relationships between the pituitary and the testis.
\end{abstract}

European Journal of Endocrinology 143 371-374

\section{Introduction}

Recombinant human interferon alpha $(\operatorname{rhIFN}-\alpha)$ is used therapeutically in malignant disorders and chronic hepatitis. Besides the immunoregulatory (1) and antiproliferative effects $(2-5)$, several endocrine changes have been documented after administration of interferon alpha (IFN- $\alpha$ ) to animals and humans (6-9). For example, IFN- $\alpha$ has been reported to stimulate cortisol release $(8,9)$ and to induce a euthyroid sick syndrome in healthy humans (10). In vitro, IFN- $\alpha$ directly inhibits testosterone production by rat testis and ovarian cells (11). In addition, IFN- $\alpha$ inhibits human chorionic gonadotropin (hCG)-stimulated testosterone secretion in cultured porcine Leydig cells $(12,13)$. The data available on the effects of IFN- $\alpha$ on testosterone production in healthy humans or patients with infectious diseases or cancer are not conclusive: both decreased (12) and unchanged $(14,15)$ testosterone concentrations following IFN- $\alpha$ were found.

To investigate the acute effects of IFN- $\alpha$ on testosterone production, we performed a saline-controlled cross-over study in six healthy men, sequentially measuring the serum concentrations of gonadotropins, testosterone, the free androgen index (FAI) and sex hormone-binding globulin (SHBG) after a bolus subcutaneous injection of rhIFN- $\alpha$.

\section{Subjects and methods}

\section{Subjects and study design}

Eight healthy males (age (mean \pm S.E.) $23 \pm 1$ years; weight $79 \pm 4 \mathrm{~kg}$; height $183 \pm 3 \mathrm{~cm}$ ) participated in the study. Medical history, physical examination and routine laboratory investigations were completely normal in all subjects. They did not use any medication and had not experienced a febrile disease in the month prior to the study. The study was approved by the Research Committee and the Medical Ethical Committee of the Academic Medical Center, Amsterdam. Written informed consent was obtained from all subjects prior to their participation.

Each subject was studied twice with an interval of at least 4 weeks. On one occasion, a bolus subcutaneous injection of rhIFN- $\alpha 2$ b ( 5 million units $/ \mathrm{m}^{2}$; ScheringPlough BV, Amstelveen, The Netherlands), dissolved in $1 \mathrm{ml}$ isotonic saline was given; on the other occasion an equivalent volume of isotonic saline was administered 
$(1000 \mathrm{~h} ; \mathrm{t}=0 \mathrm{~h})$. The order in which recombinant IFN- $\alpha$ and isotonic saline was administered to each subject was determined by balanced assignment. Volunteers were fasted overnight (from $1800 \mathrm{~h}$ ) until the end of each study period $(2200 \mathrm{~h})$.

\section{Blood sampling and assays}

Venous blood samples were obtained directly before administration of rhIFN $\alpha$ or saline, and 2, 4, 6, 8, 10 and $12 \mathrm{~h}$ thereafter. Plasma was stored at $-20^{\circ} \mathrm{C}$ until analysis. All samples from the same individual were run in the same assay. Luteinizing hormone $(\mathrm{LH})$ was measured by an immunoenzymetric assay (Immulite, DPC, Los Angeles, CA, USA; interassay coefficient of variation $2-5 \%$, intra-assay coefficient of variation $2-3 \%$ ), follicle-stimulating hormone (FSH) by RIA (Amersham International, Amersham, Bucks, UK; interassay coefficient of variation $3-6 \%$, intra-assay coefficient of variation $2-3 \%$ ), testosterone by an inhouse RIA, without extraction and chromatography and with tritiated testosterone as label (interassay coefficient of variation 5-9\%, intra-assay coefficient of variation 3-8\%) (16), SHBG by IRMA (Farmos Diagnostica, Turku, Finland; interassay coefficient of variation $3-6 \%$, intra-assay coefficient of variation $2-4 \%$ ).

\section{Calculations and statistics}

The free androgen index was calculated by multiplying the ratio of testosterone/SHBG $\times 100$.

Data are presented as means \pm s.E.M. Differences within experiments (differences compared with $t=0$ ) were tested by analysis of variance and Fisher's LSD test for multiple comparison, as indicated. Data between experiments (IFN- $\alpha$ and control data) were tested by Wilcoxon's test. A $P$ value $<0.05$ was considered to represent statistical significance.

\section{Results}

\section{Clinical features}

The clinical signs and symptoms induced by administration of rhIFN- $\alpha$ have been reported previously (17). Briefly, rhIFN- $\alpha$ provoked a mild to moderate headache, and nausea and vomiting in one subject. In all subjects, a rise in rectal body temperature was registered (maximum temperature after $8 \mathrm{~h}: 38.4 \pm$ $0.2{ }^{\circ} \mathrm{C}$ ), preceded by mild to moderate chills. Systolic blood pressure increased (from $125 \pm 2$ to a maximum of $140 \pm 4 \mathrm{mmHg})(P<0.01)$, whereas diastolic blood pressure decreased (from $81 \pm 2$ to a minimum of $66 \pm 2 \mathrm{mmHg})(P<0.001)$.

\section{LH and FSH}

There were no differences in basal concentrations of LH and FSH between the control day and the rhIFN- $\alpha$ study
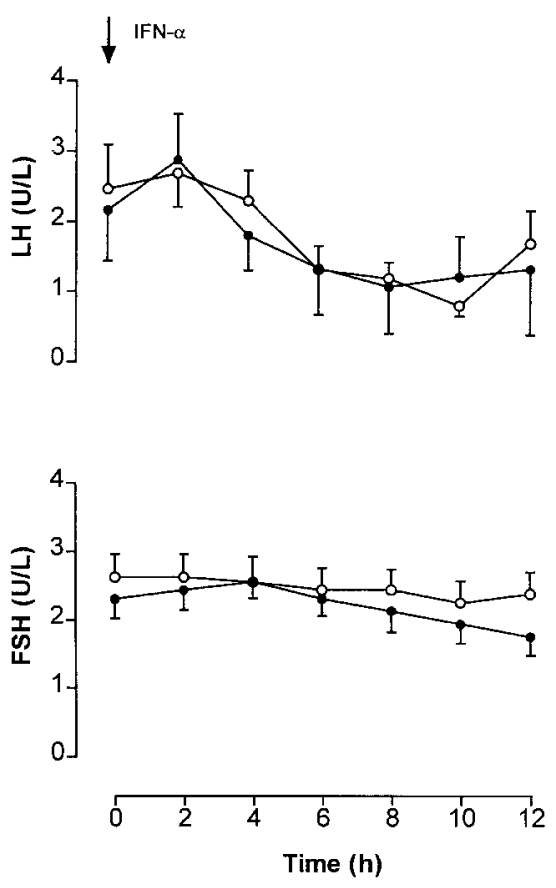

Figure 1 Plasma LH and FSH concentrations (means \pm S.E.M.) after rhIFN- $\alpha$ administration (closed circles) or placebo administration (open circles) at $\mathrm{t}=0 \mathrm{~h}$. There was no effect of $\operatorname{rhIFN}-\alpha$ on plasma LH and FSH concentrations.

day (Fig. 1). All baseline concentrations were within the reference range. Plasma LH and FSH levels were not affected by rhIFN- $\alpha$ compared with saline.

\section{Testosterone, free androgen index and SHBG}

Preinjection plasma testosterone, FAI and SHBG levels were not different between both study periods (Fig. 2). rhIFN- $\alpha$ induced a marked decrease in serum testosterone and FAI levels, becoming significant after six hours and reaching a nadir after twelve hours (5.49 \pm $0.51 \mathrm{nmol} / \mathrm{l}, \quad P<0.02$ vs control and $32.1 \pm 5.3$, $P<0.03$ vs control respectively). SHBG levels were not affected by rhIFN- $\alpha$.

\section{Discussion}

This study evaluated the acute effects of rhIFN- $\alpha$ aministration on the pituitary-testicular axis in healthy humans. The data show that subcutaneous administration of rhIFN- $\alpha$ to humans induces an acute decrease in both testosterone and FAI without any alterations in plasma levels of $\mathrm{LH}$ or $\mathrm{FSH}$, indicating that rhIFN- $\alpha$ affects the hypothalamus-pituitary-testicular (HPT) axis at the testicular level.

The acute effects $(<12 \mathrm{~h})$ of IFN- $\alpha$ on testosterone concentrations in healthy subjects have not been documented before. The data available on the effects of 

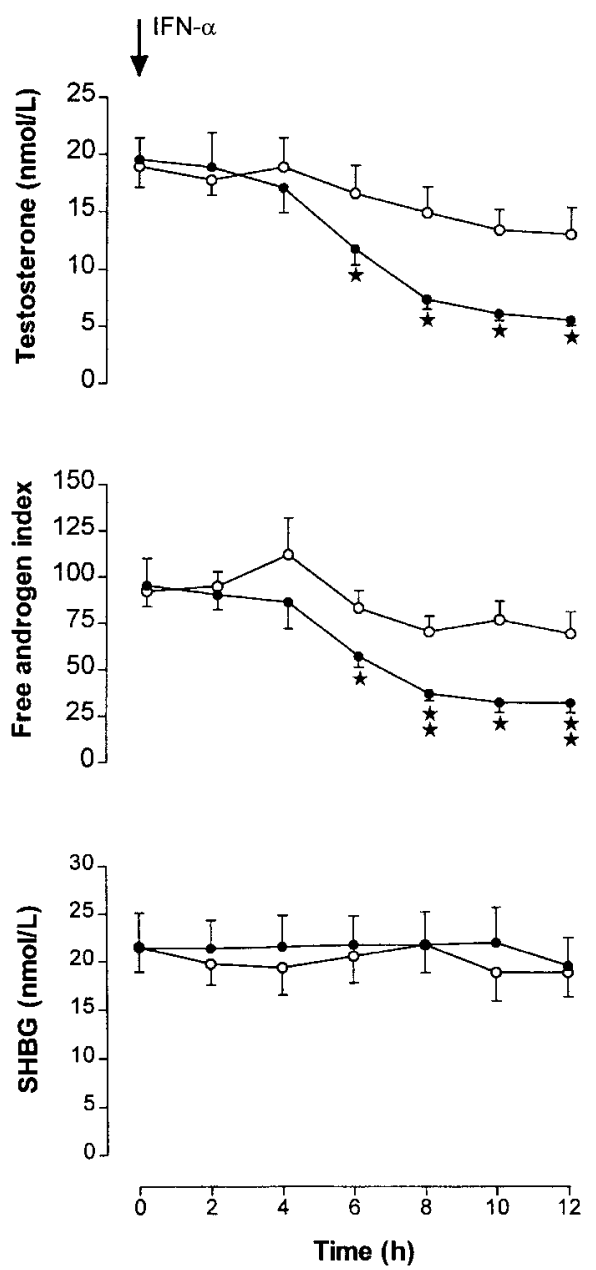

Figure 2 Plasma testosterone and SHBG concentrations and FAl (means \pm S.E.M.) after rhIFN- $\alpha$ administration (closed circles) or placebo administration (open circles) at $\mathrm{t}=0 \mathrm{~h}$. ${ }^{*} P<0.02$, ${ }^{\star \star} P<0.03$ vs the corresponding value of the control day.

IFN- $\alpha$ in healthy humans or patients with infectious diseases or cancer are not conclusive, which is probably related to differences in study design. Orava et al. reported a decrease in serum testosterone concentration measured daily during daily injections of IFN- $\alpha$ $\left(1.5-3 \times 10^{6} \mathrm{U}\right)$ for four to ten days in three healthy men (12). In that study, testosterone concentrations returned to control levels after cessation of treatment (12). Piazza et al. documented unchanged serum free testosterone levels, measured every three months during IFN- $\alpha\left(1 \times 10^{6} \mathrm{U}\right)$ therapy thrice weekly for twelve months in patients affected by chronic hepatitis C (14). The same was found by Bareca et al., who reported no change in serum free testosterone and LH concentrations, measured every two months during IFN- $\alpha$ $\left(3 \times 10^{6} \mathrm{U}\right)$ thrice weekly for six months (15). Since we found a decrease in testosterone concentrations within twelve hours after one injection of $\operatorname{rhIFN}-\alpha$, which was also found by Orava et al. during short term treatment with rhIFN- $\alpha$ (<10 days) (12), whereas no change was found during chronic administration (6-12 months) of rhIFN- $\alpha(14,15)$, it is possible that there is a difference between the acute and chronic effects of rhIFN- $\alpha$, such as has been documented for the effects of rhIFN- $\alpha$ on thyroid hormone concentrations $(6,7,10)$. Since in our study no measurements of testosterone concentrations were performed later than $12 \mathrm{~h}$ after $\operatorname{rhIFN}-\alpha$ administration, no conclusions can be drawn about the duration of the hormone effect.

We did not find any effect of administration of rhIFN- $\alpha$ to humans on concentrations of FSH and LH. However, in ovariectomized cows, recombinant bovine interferon- $\alpha$ decreases plasma concentrations of LH two to six hours after injection (18). This discrepancy might be related to interspecies differences (19). Considering the unchanged LH levels several hours after the injection of rhIFN- $\alpha$, our results point to an effect of IFN- $\alpha$ at the level of the testis as well as to an altered feedback relationship between the pituitary and the testis, since one would expect gonadotropin concentrations to increase when testosterone concentrations decrease. Our findings are supported by data from in vitro animal studies. For instance, IFN- $\alpha$ inhibits testosterone production by rat testis and ovarian cells (11) and hCG-stimulated testosterone secretion in cultured porcine Leydig cells (13, 19). Interestingly, since IFN- $\alpha$ production increases in response to viral infections, it could be speculated that IFN- $\alpha$ might be a mediator in the decrease in testosterone concentrations during viral orchitis.

It is unclear whether $\operatorname{rhIFN}-\alpha$ decreases testosterone concentrations directly or indirectly. Critical illness frequently affects the HPT axis, resulting in decreased plasma concentrations of testosterone (20-22). Concomitant activation of other endocrine pathways may be of importance in the etiology of the altered HPT function in systemic disease. Increased circulating levels of corticosteroids may directly inhibit testicular testosterone production (23). In addition, raised levels of epinephrine have been reported to lower plasma testosterone concentrations in man (24). rhIFN- $\alpha$ increases concentrations of plasma cortisol and epinephrine (17). The rise in cortisol could contribute to the decrease in testosterone concentrations, as maximum concentrations of cortisol were reached after eight hours (17) and the inhibitory effects of cortisol in vitro were apparent after about six hours (23). Infusion of epinephrine into healthy men induces a rapid decrease in testosterone levels (24). Therefore, it is likely that increased levels of cortisol and epinephrine induced by IFN- $\alpha$ are, at least in part, involved in the decrease in testosterone concentrations.

In conclusion, this study demonstrates that rhIFN- $\alpha$ induces an acute decrease in both testosterone and FAI in healthy humans without any alterations in plasma levels of LH, FSH or SHBG, suggesting that rhIFN- $\alpha$ affects the HPT axis at the testicular level, 
either directly or indirectly, and that rhIFN- $\alpha$ changes feedback relationships between the pituitary and the testis.

\section{Acknowledgements}

The authors gratefully thank the workers of the Laboratory of Endocrinology and Radiochemistry of our Institute.

\section{References}

1 Pfeffer LM, Dinarello CA, Herberman LB, Williams BR, Borden EC, Bordens $\mathrm{R}$ et al. Biological properties of recombinant $\alpha$ interferons: 40th anniversary of the discovery of interferons. Cancer Research 199858 2489-2499.

2 Gasl G \& Huber C. The biology of interferon actions. Blut 198856 193-199.

3 Gressler I \& Bourali C. Antitumor effects of interferon preparations in mice. Journal of the National Cancer Institute 197045 365-374.

4 Wells V \& Malluci L. Expression of the 2-5A system during the cell cycle. Experimental Cell Research 1985159 27-36.

5 Houghton AN, Thomson TM, Gross D, Oettgen HF \& Olfd LJ. Surface antigens of melanoma and melanocytes: specificity of induction of Ia antigens by human $\alpha$ interferon. Journal of Experimental Medicine $1984160255-269$.

6 Berris B \& Feinman SV. Thyroid dysfunction and liver injury following alpha-interferon treatment of chronic viral hepatitis. Digestive Diseases and Sciences 199136 1657-1660.

7 Baudin E, Marcellin P, Pouteau M, Colas-Linhart N, Le Floch JP, Lemmonier $\mathrm{C}$ et al. Reversibility of thyroid dysfunction induced by recombinant alpha interferon in chronic hepatitis C. Clinical Endocrinology $199339657-661$.

8 Scott GM, Ward RJ, Wright DJ, Robinson JA, Onwubalil JG \& Gauci CL. Effects of cloned interferon alpha in two normal volunteers: febrile reactions and changes in circulating corticosteroids and trace metal. Antimicrobial Agents and Chemotherapy 198323 589-594.

9 Roosth J, Pollard RB, Brown SL \& Meyer WJ. Cortisol stimulation by recombinant interferon- $\alpha 2$. Journal of Neuroimmunology 1986 12 311-316.

10 Corssmit EPM, Heyligenberg R, Endert E, Sauerwein HP \& Romijn JA. Acute effects of interferon- $\alpha$ administration on thyroid hormone metabolism in healthy men. Journal of Clinical Endocrinology and Metabolism 199580 3140-3144.

11 Montor JM, Mendoza ME \& Romano MC. Effect of human and murine interferon-alpha on steroid production by rat ovarian cells. Life Sciences 199862 1733-1744.

12 Orava M, Cantell K \& Vihko R. Treatment with preparations of human leukocyte interferon decreases serum testosterone concentrations in men. International Journal of Cancer 198638 295-296.

13 Orava M. Comparison of the inhibitory effects of interferon- $\alpha$ and $-\gamma$ on testosterone production in the porcine Leydig cell culture. Journal of Interferon Research 19899 135-141.

14 Piazza M, Tosone G, Borgia G, Orlando R, Fenzi G, Vitale M et al. Long-term interferon-alpha therapy does not affect sex hormones in males with chronic hepatitis C. Journal of Interferon and Cytokine Research 199717 525-529.

15 Barreca T, Picciotto A. Franceschini R, Varagona G, Garibaldi A, Valle F et al. Sex hormones and sex-hormone binding globulin in males with chronic viral hepatitis during recombinant interferon-alpha 2b therapy. Journal of Interferon Research 1993 $13209-211$.

16 Pratt JR, Wiegman T, Lappohn RE \& Woldring MG. Estimation of plasma testosterone without extraction and chromatography. Clinica Chimica Acta $197559337-346$.

17 Corssmit EPM, Heyligenberg R, Endert E, Ackermans MT, Sauerwein HP \& Romijn JA. Endocrine and metabolic effects of interferon- $\alpha$ in humans. Journal of Clinical Endocinology and Metabolism 199681 3265-3269.

18 Barros CM, Betts JG, Thatcher WW \& Hansen PJ. Possible mechanisms for reduction of circulating concentrations of progesterone by interferon- $\alpha$ in cows: effects on hyperthermia, luteal cells, metabolism of progesterone and secretion of LH. Journal of Endocrinology 1992133 175-182.

19 Orava M. Cantell K \& Vihko R. Human leukocyte interferon inhibits human chorionic gonadotropin stimulated testosterone production by porcine Leydig cells in culture. Biochemical and Biophysical Research Communications 1985127 809-814.

20 Woolf PD, Hamill RW, McDonald JV, Lee LA \& Kelly M. Transient hypogonadotropic hypogonadism caused by critical illness. Journal of Clinical Endocrinology and Metabolism 198560 444-450.

21 Vogel AV, Peake GT \& Rada RT. Pituitary-testicular axis dysfunction in burned men. Journal of Clinical Endocrinology and Metabolism $198560658-665$.

22 Croxson TS, Chapman WE, Miller LK, Levit CD, Senie R \& Zumoff B. Changes in the hypothalamic-pituitary-gonadal axis in human immunodeficiency virus-infected homosexual men. Journal of Clinical Endocrinology and Metabolism 198968 317-321.

23 Bambino TH \& Hsueh AJW. Direct inhibitory effect of glucocorticoids upon testicular luteinizing hormone receptor and steroidogenesis in vivo and in vitro. Endocrinology 1981108 $2142-2148$.

24 Levin J, Lloyd CW, Lobotsky J \& Friedrich EH. The effect of epinephrine on testosterone production. Acta Endocrinologica $196755184-192$.

Received 31 December 1999

Accepted 9 May 2000 